\title{
MiR-143-5p Deficiency Triggers EMT and Metastasis by Targeting HIF-1 $\alpha$ in Gallbladder Cancer
}

\author{
Min $\mathrm{He}^{\mathrm{a}}$ Ming Zhan ${ }^{\mathrm{a}}$ Wei Chen ${ }^{\mathrm{a}}$ Sunwang $\mathrm{Xu}^{\mathrm{a}}$ Manmei Long $^{\mathrm{b}}$ Hui Shen ${ }^{\mathrm{a}}$ \\ Yongheng Shi ${ }^{b}$ Qiang Liu ${ }^{b}$ Man Mohanc Jian Wang ${ }^{a}$
}

${ }^{a}$ Department of Biliary-Pancreatic Surgery, ${ }^{b}$ Department of Pathology, Renji Hospital, 'Department of Biochemistry and Molecular Cell Biology, Shanghai Key Laboratory of Tumor Microenvironment and Inflammation, Institutes of Medical Sciences, Shanghai Jiao Tong University, School of Medicine, Shanghai, China

\section{Key Words}

Gallbladder cancer • miR-143-5p • HIF-1 $\bullet$ Epithelial-mesenchymal transition • Metastasis

\begin{abstract}
Background/Aims: Early metastasis plays a pivotal role in tumor-caused death in gallbladder cancer (GBC) patients. Increasing evidence suggest that miR-143-5p is an active player involved in cancer metastasis and a potential therapeutic target. However, its role in the development of GBC cells remains unclear. The aim of this study is to reveal the inhibiting effects of miR-143-5p on the proliferation and metastasis in GBC. Methods: Quantitative real-time PCR were used to investigate miR-143-5p and its target HIF- $1 \alpha$ mRNA levels. Protein expression was measured by immunohistochemistry and western blot. The function and regulation mechanism of miR143-5p was confirmed by MTS, colony formation, wound healing, transwell, and luciferase reporter assays. Results: miR-143-5p was first found significantly reduced in GBC tissues compared with corresponding noncancerous gallbladder tissues. In addition, miR-143-5p deficiency correlated well with larger tumor size, advanced TNM stage, and poorer survival rate. In vitro, miR-143-5p addition dramatically suppressed GBC cells proliferation, migration and invasion, whereas miR-143-5p antisense led the opposite effects. Further elucidating the molecular mechanism inside, we found miR-143-5p exerted its inhibitory function through downregulating the expression of HIF-1 $\alpha$, which further reduced Twist1 and impeded epithelial-mesenchymal transition (EMT). Conclusions: Altogether, our studies identified a novel regulator, miR-143-5p, implicated in GBC prognosis through targeting HIF-1 $\alpha$ /EMT related signaling pathway, which could serve as a biomarker and therapeutic target for GBC.
\end{abstract}

(C) 2017 The Author(s)

Published by S. Karger AG, Basel

\section{Introduction}

As the most common biliary tract tumor worldwide, especially in Asia, Andean area and Eastern Europe, Gallbladder cancer (GBC), is a highly lethal disease [1]. GBC has an extremely

M. He, M. Zhan and W. Chen contributed equally to this work. 
poor prognosis with the median survival of 9.2 months and the 5-year survival is about $5 \%$ $[2,3]$. The high proliferation rate and easy metastasis propensity of GBC made its therapy especially difficult. Most GBC patients, once diagnosed, had lost the best time for surgical treatment. Clearly, identifying the precise mechanism underlying would be beneficial for those patients.

MicroRNAs are small, noncoding (18-25 nucleotidesin length) RNA molecules, which is actively involved in regulating many genes' expression [4, 5]. Through targeting and degrading specific mRNAs, microRNAs can act as either oncogene or tumor suppressor gene. Evidences have given that microRNAs are implicated in many biological process of cancer, like proliferation, apoptosis, drug resistance, invasion and metastasis [6]. In GBC, numerous microRNAs aberrations have been reported and correlated well with GBC patients' prognosis [7]. miR-143-5p, a previously identified tumor suppressor, located in the 5q32 chromosomal region, have been found implicated in various kinds of cancers, including lung, renal, liver, esophageal, gastric and breast cancer [8-13]. But whether miR-143-5p executed the same role in GBC cancer has never been investigated.

Epithelial-mesenchymal transition (EMT), several oncogenic cues have been suggested could increase GBC cells growth and stemness through promoting EMT process [14, 15]. Hypoxia-inducible factor- $1 \alpha$ subunit (HIF- $1 \alpha$ ), a key factor in resisting oxidative stress, could also promote aggressive phenotype of cancer cells through different types of intracellular signal transduction pathways, including EMT activation [16-22]. Therefore, inhibiting HIF$1 \alpha$ activation could be a favorable target for preventing GBC recurrence.

In this study, we demonstrated that reduced miR-143-5p in GBC tissue could be an important contributor to its increased growth, and enhancive migration and invasion. miR143-5p overexpression inhibited GBC cell proliferation, migration and invasion in vitro and in vivo. We also showed mechanistically that miR-143-5p acts as a tumor suppressor in inhibiting the aggressive GBC behavior by HIF-1 $\alpha$ and EMT pathway. Furthermore, evidence for miR-143-5p functionality in GBC also extended to clinicopathological features and prognosis of GBC patients, and may be considered for the development of potential therapeutics against GBC.

\section{Materials and Methods}

\section{Tissue samples}

A total of 82 GBC formalin-fixed, paraffin-embedded (FFPE) cancer specimens were retrieved from GBC patients who underwent surgical resection of the gallbladder at Renji Hospital from January 2004 to December 2013. Among the 82 GBC patients, thirty-six pairs of samples fresh tumor tissues and the corresponding noncancerous gallbladder (CNG) tissues were collected immediately after the surgical removal and snap-frozen in liquid nitrogen for total RNA extraction. All the clinicopathological features of the enrolled GBC patients are collected and shown in Table 1. The sample collection and feature analysis of GBC patients was approved by the Ethical Committee of Renji Hospital, Shanghai Jiao Tong University School of Medicine, and informed written consent for the acquisition was obtained from all patients.

Cell lines

The human GBC cell lines GBC-SD and SGC-996 were purchased from the Cell Bank of Type Culture Collection of Chinese Academy of Sciences and Tongji University (Shanghai, China), respectively. NOZ human gallbladder cancer cell line was obtained from the Health Science Research Resources Bank (Japan). GBCSD was cultured in high-glucose DMEM (Gibco, USA). SGC-996 cells were cultured in RPMI-1640 medium (Gibco). NOZ cells were cultured in Willian's E medium (Gibco). All of the above mediums were supplemented with $100 \mathrm{U} / \mathrm{mL}$ penicillin, $100 \mu \mathrm{g} / \mathrm{mL}$ streptomycin and $10 \%$ fetal bovine serum. Cells were incubated in a $37^{\circ} \mathrm{C}$ humidified atmosphere with $5 \% \mathrm{CO}_{2}$.

RNA extraction and quantitative real-time PCR (Q-PCR) analysis

Total RNA was isolated from freshly-frozen tissues or cells by using TRI Reagent (Sigma, USA), and FFPE tissues by using miRNeasy FFPE Kit (Qiagen, USA) according to the manufacturer's instructions. After 


\section{Cellular Physiology Cell Physiol Biochem 2017;42:2078-2092 \begin{tabular}{ll|l} 
and Biochemistry Published online: August 11, 2017 & $\begin{array}{l}\text { (c) } 2017 \text { The Author(s). Published by S. Karger AG, Basel } \\
\text { www.karger.com/cpb }\end{array}$
\end{tabular}}

He et al.: MiR-143-5p Inhibits Gallbladder Cancer Metastasis

Table 1. Correlation between miR-143-5p expression and clinicopathological features

\begin{tabular}{|c|c|c|c|c|c|}
\hline Characteristics & No. of patients $(n=82)$ & Low expression $(n=48)$ & High expression $(n=34)$ & $x^{2}$ & Pvalue \\
\hline Gender & & & & \multirow{3}{*}{0.009} & \multirow{3}{*}{0.926} \\
\hline Female, n (\%) & $55(67.1)$ & $32(66.7)$ & $23(67.6)$ & & \\
\hline Male, n (\%) & 27 (32.9) & $16(33.3)$ & $11(32.4)$ & & \\
\hline Age, y & & & & & \multirow{4}{*}{0.428} \\
\hline$\geq 60, \mathrm{n}(\%)$ & $64(78.0)$ & $36(75.0)$ & $28(82.4)$ & \multirow{3}{*}{0.628} & \\
\hline$<60, \mathrm{n}(\%)$ & $18(22.0)$ & $12(25.0)$ & $6(17.6)$ & & \\
\hline Ever smoke & & & & & \\
\hline Yes, n (\%) & $21(25.6)$ & $14(29.2)$ & 7 (20.6) & \multirow{3}{*}{0.769} & \multirow{2}{*}{0.381} \\
\hline No, n (\%) & $61(74.4)$ & $34(70.8)$ & $27(79.4)$ & & \\
\hline Gallstone status & & & & & \multirow{4}{*}{0.651} \\
\hline Yes, n (\%) & $67(81.7)$ & $40(83.3)$ & $27(79.4)$ & \multirow{3}{*}{0.205} & \\
\hline No, $n[\%)$ & 15 (18.3) & $8(16.7)$ & 7 (20.6) & & \\
\hline CA19-9, U/ml & & & & & \\
\hline z 37, n (\%) & $49(59.8)$ & $30(62.5)$ & $19(55.9)$ & \multirow{2}{*}{0.362} & \multirow{2}{*}{0.547} \\
\hline$<37, \mathrm{n}(\%)$ & $33(40.2)$ & 18 (37.5) & $15(44.1)$ & & \\
\hline Tumor size, $\mathrm{cm}$ & & & & \multirow{4}{*}{7.849} & \multirow{4}{*}{0.005} \\
\hline$\geq 5, n(\%)$ & $53(64.6)$ & 37 (77.1) & $16(47.1)$ & & \\
\hline$<5, \mathrm{n}(\%)$ & $29(35.4)$ & $11(22.9)$ & $18(52.9)$ & & \\
\hline TNM stage & & & & & \\
\hline $\mathrm{I}, \mathrm{I}$ & $31(37.8)$ & $13(27.1)$ & $18(52.9)$ & \multirow{2}{*}{5.660} & \multirow{2}{*}{0.017} \\
\hline III,IV & $51(62.2)$ & 35 (72.9) & $16(47.1)$ & & \\
\hline
\end{tabular}

determining the concentration and A260/A280 absorbance ratio in Nanodrop 8000 spectrophotometer (Thermo Fisher Scientific, USA), total RNA was reverse-transcribed with Reverse Transcriptase M-MLV kit (Invitrogen). The expression of mRNA and miRNA were analyzed by using SYBR Premix Ex Taq (Takara, Japan) and conducted Q-PCR on the Applied Biosystems ViiATM 7 Real-Time PCR System (Applied Biosystems, USA). All Q-PCR reactions were done in triplicate. The U6 RNA or GAPDH were used as the endogenous controls, and the $2^{-\Delta \Delta C T}$ equation was used to calculate the relative quantification of mRNA and miRNA [23].

\section{Cell transfection}

HIF- $1 \alpha$ expression plasmid was generated by insertion of the CDS of HIF- $1 \alpha$ into a pcDNA 3.1 vector (Invitrogen). The mimic miR-143-5p, mimic control, antisense miR-143-5p and antisense control were purchased from GenePharma (China). GBC cells were seeded into 6-well plates, and then transfected with HIF-1 $\alpha$ overexpression vector or empty vector, mimic miR-143-5p or mimic control, and antisense miR-143$5 \mathrm{p}$ or antisense control by using lipofectamine 2000 (Invitrogen) according to the protocols for $48 \mathrm{~h}$.

\section{Protein extraction and western blot analysis}

Total protein was extracted from the GBC cells using RIPA lysis buffer supplemented with PMSF and proteinase inhibitor cocktail. The protein concentration was measured by using BCA assay. Equivalent protein of each group were separated by SDS-PAGE and transferred onto a PVDF membranes (Millipore, USA), and then the blots were blocked in a solution of $5 \%$ skimmed milk, Tris-bufferred saline with 0.05 $\%$ Tween 20 (TBST) for $2 \mathrm{~h}$ at room temperature. Target protein was probed with primary antibodies overnight at $4{ }^{\circ} \mathrm{C}$ and horseradish peroxidase-conjugated secondary antibodies at room temperature for 2h. Protein bands were visualized with enhanced chemiluminescence reagents (Millipore) in ChemiDoc MP chemiluminescence system (Biorad, USA). Antibodies against HIF-1 $\alpha$ (1:300, sc-13515, Santa Cruz), VEGF (1:500, No.9698, Cell Signaling Technology), TWIST1 (1:500, sc-6070, Santa Cruz), $\beta$-catenin (1:500, sc7963, Santa Cruz), Vimentin (1:1000, sc-53464, Santa Cruz), E-cadherin (1:500, SAB4503751, Sigma), Ki67 (1:1000, No.9449, Cell Signaling Technology), PCNA (1:1000, No.2586, Cell Signaling Technology), and $\beta$-actin (1:2000, A5316, Sigma) were purchased.

\section{Immunohistochemistry (IHC) assays}

FFPE tissue samples were sectioned into $4 \mu \mathrm{m}$ thick sections for IHC by using a standard immunestaining protocol, and stained by antibodies against HIF-1 $\alpha$ (1:50, sc-13515, Santa Cruz), Ki-67 (1:100, sc6070, Santa Cruz), TWIST1 (1:50, sc-6070, Santa Cruz), $\beta$-catenin (1:50, sc-7963, Santa Cruz), Vimentin (1:100, sc-53464, Santa Cruz), E-cadherin (1:50, SAB4503751, Sigma). After routinely deparaffinization by treating with xylene and rehydrated in gradient ethanol solution, sections were incubated with citrate buffer solution at $100{ }^{\circ} \mathrm{C}$ for $1 \mathrm{~min}$ for antigen retrieval. Slides were then permeabilized in $0.1 \%$ Triton $\mathrm{X}-100$, and incubated overnight at $4{ }^{\circ} \mathrm{C}$ with primary antibody mentioned above. Subsequently, the slides 


\section{Cellular Physiology Cell Physiol Biochem 2017;42:2078-2092 \begin{tabular}{l|l|l} 
and Biochemistry Published online: August 11, 2017 & $\begin{array}{l}\text { C) } 2017 \text { The Author(s). Published by S. Karger AG, Basel } \\
\text { www.karger.com/cpb }\end{array}$ \\
\hline
\end{tabular}}

He et al.: MiR-143-5p Inhibits Gallbladder Cancer Metastasis

were incubated with secondary antibody at $37^{\circ} \mathrm{C}$ for $1 \mathrm{~h}$. Finally, 3,3-diaminobenzidine tetrahydrochloride was used as the colorizing reagent, and hematoxylin was used to counter stain nuclei. The stained sections were photographed by using light microscopy equipped with camera (Olympus, Japan).

Dual-luciferase reporter assay

The 3'-UTR sequence of HIF-1 $\alpha$ containing the predicted miR-143-5p targeting site (WT: ACUGCAC) and the mutated 3'-UTR sequence within the predicted target site (MU: AGUGCAC) was synthesized and cloned into a pmirGLO Dual-Luciferase miRNA Target ExpressionVector (Promega). The luciferase reporter assay was performed by the Dual-Luciferase Reporter Assay System (Promega) as previously described [24].

\section{Colony formation and cell proliferation assay}

About 500 cells GBC cells were seeded in 6-well plates and cultured for 14 days. Colony counts were estimated after they fixed with $90 \%$ ethanol for $15 \mathrm{~min}$ and stained by $0.1 \%$ crystal violet solution for 20 min. For cell proliferation assay, GBC cells $\left(1 \times 10^{3}\right)$ were seeded in 96-well plates after transfection, and the cell number were assessed by using 3-(4,5-dimethylthiazol-2-yl)-5-(3-carboxymethoxyphenyl)-24-sulfophenyl)-2H-tetrazolium (MTS; Promega, USA) in microplate reader.

\section{Wound healing assay and cell invasion assay}

For wound healing assay, GBC cells were seeded into 6-well plates and grown to confluence. Wounds were generated by scraping the confluent cell monolayers by using a $200-\mu \mathrm{L}$ pipette tip. Cells were extensively rinsed to remove cellular debris with PBS, and then cultured in FBS-free medium. Photomicrographs were taken under a microscope at $0 \mathrm{~h}$ and $24 \mathrm{~h}$. The percent migration distance of GBC cells was determined by comparing differences in wound width. The invasion abilities of the GBC cells were detected by using 24well transwell plate with $8-\mu$ m poresize polycarbonate membrane (Corning, USA). GBC cells $\left(2 \times 10^{4}\right)$ in $100 \mu \mathrm{L}$ of serum-free medium were seeded to the upper chambers with Matrigel (BD) coated membrane for $36 \mathrm{~h}$, while the lower chamber filled with $500 \mu \mathrm{L}$ medium with $10 \% \mathrm{FBS}$. After incubation, the upper side of the filters contained the non-invasion cells were detached using cotton swabs, and then fixed with $90 \%$ ethanol for $15 \mathrm{~min}$. The cells in the lower side of filters were stained with $0.1 \%$ crystal violet solution for $20 \mathrm{~min}$. Six random fields of each chamber were photographed and the cells stained by crystal was counted.

Subcutaneous and liver metastasis tumor assay in a nude mouse model

The recombinant plasmid containing CDS of miR-143-5p (pLenti6/V5-GW/ miR-143-5p, Thermo Fisher Scientific) or scrambled miRNA and the packaging plasmids (pLP1, pLP2, and pLP/VSVG) were cotransfected into HEK293FT cells by using Lipofectamine 2000 transfection reagent. After transfection for $72 \mathrm{~h}$, the viruses were harvested and then transduced into NOZ cells with $4 \mu \mathrm{g} / \mathrm{ml}$ polybrene (Sigma). The stable transfected cells were selected by $2.5 \mu \mathrm{g} / \mathrm{ml}$ puromycin and validated by immunoblotting. Twelve male BALB/c athymic nude mice (4-weeks-old; 15-25 g) were purchased from the Shanghai Laboratory Animal Center (China), and randomly divided into two groups (6 mice/group). All the nude mice were housed in specific-pathogen-free conditions, and all in vivo experiments strictly performed accordance with the recommendations in the Guide for the Care and Use of Laboratory Animals of Shanghai Jiao Tong University. A total $2 \times 10^{6} \mathrm{NOZ}$ cells stably overexpressed miR-143-5p and scrambled miRNA in $100 \mu \mathrm{l}$ medium were subcutaneously transplanted into the mouse left flank of two groups, respectively. Tumor growth curve was measured with a caliper every 3 days from the $7^{\text {th }}$ day to $40^{\text {th }}$ day. Tumor volume analysis was based on the equation: $V=\left(\right.$ length $\times$ width $\left.^{2}\right) / 2$ [25] On day 40, all the mice were euthanized, and the xenografted tumors were dissected out for weighing, H\&E and IHC staining. All the mice livers were also harvested for counting the number of metastases.

Bioinformatics of miR-143-5p target gene

The bioinformatics of miR-143-5p target gene were performed by computer-aided algorithms, TargetScan Release 7.0 (http://www.targetscan.org/vert_71/) and miRDB (http://mirdb.org).

Statistical analysis

All experiments were performed in triplicate. The data were expressed as the mean \pm standard error of mean (SEM). Comparisons between two groups were performed with the paired Student's test or 
independent Student's t-test (two-tailed). For multiple comparisons, the Tukey-Kramer honestly significant difference was applied following ANOVA. Kaplan-Meier plots and log-rank tests were used for POS analysis. Multivariate analysis was performed using Cox's proportional hazards model. The Pearson $\chi^{2}$ test was used to analyze the bivariate correlations between miR-143-5p expression and HIF-1 $\alpha$ mRNA expression. The association analysis between miR-143-5p expression and clinicopathological features was conducted by using $\chi^{2}$ test. SPSS 17.0 for Windows was used for all statistical analysis (IBM, USA). $P<0.05$ was considered statistically significant.

\section{Results}

Lower miR-143-5p expression in GBC and its correlation with clinicopathological features in $G B C$ patients

miR-143-5p was previously found involved in various kinds of tumors [8-13], but whether and how it implicated in GBC development has never been investigated. To identify the possible relationship, we first examined miR-143-5p expression in 32 GBC and CNG tissues by Q-PCR. Interestingly, a significantly reduced miR-143-5p expression in GBC tissues compared with matched normal tissues was detected (Fig. 1A). A lower miR-143$5 \mathrm{p}$ in different GBC cell lines (NOZ, GBC-SD, SGC-996) compared with normal gallbladder epithelium cell (GBE) was also observed (Fig. 1B). For further investigating the relationship between miR-143-5p expression and the clinicopathological features and prognosis, we classified the $82 \mathrm{GBC}$ patients according to their respective miR-143-5p expression level

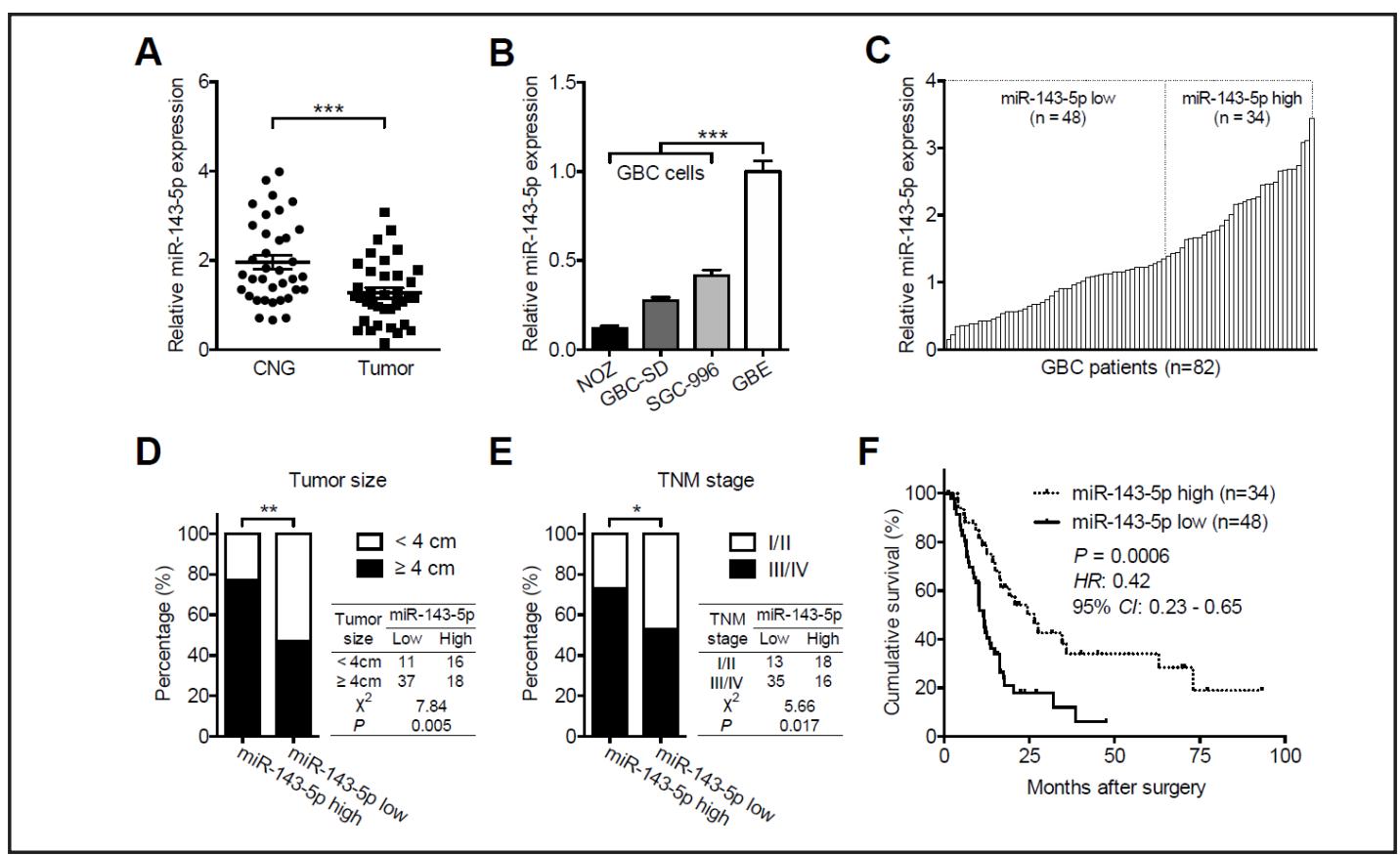

Fig. 1. Reduced miR-143-5p expression in GBC tissues and cell lines and correlated with poor prognosis. (A) Reduced miR-143-5p expression in paired GBC tissues with the corresponding noncancerous gallbladder (CNG). (B) Reduced miR-143-5p expression in GBC cell lines (NOZ, GBC-SD, SGC-996) compared with normal gallbladder epithelium cell (GBE). (C) Eighty-two GBC patients were separated into miR-143-5p low group and miR-143-5p high group based on the mean value of miR-143-5p expression. (D) Tumors size comparison according to miR-143-5p expression. The number of patients carrying tumors larger than $4 \mathrm{~cm}$ was less in miR-143-5p elevated group. (E) Advanced TNM stage in GBC patients with lower miR-143-5p expression. (F) Improved cumulative survival rate observed in patients with reduced miR-143-5p expression. U6 small nuclear RNA was used as an internal control in Q-PCR. ${ }^{*} P<0.05$; ${ }^{* *} P<0.01$; *** $P<0.001$; Bar, SEM; Student's t test.

\section{KARGER}


Table 2. Univariate analysis and multivariate analysis of miR-143-5p expression and clinicopathological features for prognostic factors in GBC patients

\begin{tabular}{lllllll}
\hline Prognostic factors & \multicolumn{3}{c}{ Univariate analysis } & \multicolumn{3}{c}{ Multivariate analysis } \\
Gender (Female/Male) & HR & $95 \% \mathrm{CI}$ & P value & HR & $95 \% \mathrm{CI}$ & P value \\
\hline Age $(\geq 60 /<60, \mathrm{y})$ & 0.96 & $0.32-2.86$ & 0.937 & & & \\
Ever smoke (Yes/No) & 0.99 & $0.52-1.86$ & 0.968 & & & \\
Gallstone status (Yes/No) & 0.31 & $0.08-1.29$ & 0.107 & & & \\
CA19-9 $(\geq 37 /<37, \mathrm{U} / \mathrm{ml})$ & 0.59 & $0.31-1.12$ & 0.107 & & & \\
Tumor size $(\geq 4 /<4, \mathrm{~cm})$ & 0.47 & $0.23-0.97$ & 0.042 & 0.56 & $0.29-1.08$ & 0.084 \\
TNM stage ( I , II /III,IV) & 0.28 & $0.13-0.61$ & 0.001 & 0.37 & $0.15-0.65$ & $\mathbf{0 . 0 0 2}$ \\
miR-143-5p (low/high) & 0.42 & $0.23-0.65$ & 0.001 & 0.45 & $0.25-0.70$ & $\mathbf{0 . 0 0 2}$ \\
\hline
\end{tabular}

Fig. 2. In vitro altered miR-143$5 \mathrm{p}$ expression influenced GBC cells proliferation ability. (A) Increasing miR-143-5p expression impeded cell proliferation examined by MTS assay in GBC (NOZ, GBC-SD and SGC-996) cell lines. (B) Reducing miR-143-5p expression accelerated proliferation cells in GBC cell lines. (C) Clonal formation ability assessed in GBC cells with altered miR-143-5p expression. All the experiments were repeated three times. (D) Flow cytometry analysis of cell apoptosis rate in GBC (NOZ, GBCSD and SGC-996) cells transfected with miR-143-5p mimic, antisense and negative control. $* P<0.05$; ** $P<0.01$; Bar, SEM; Student's t test.

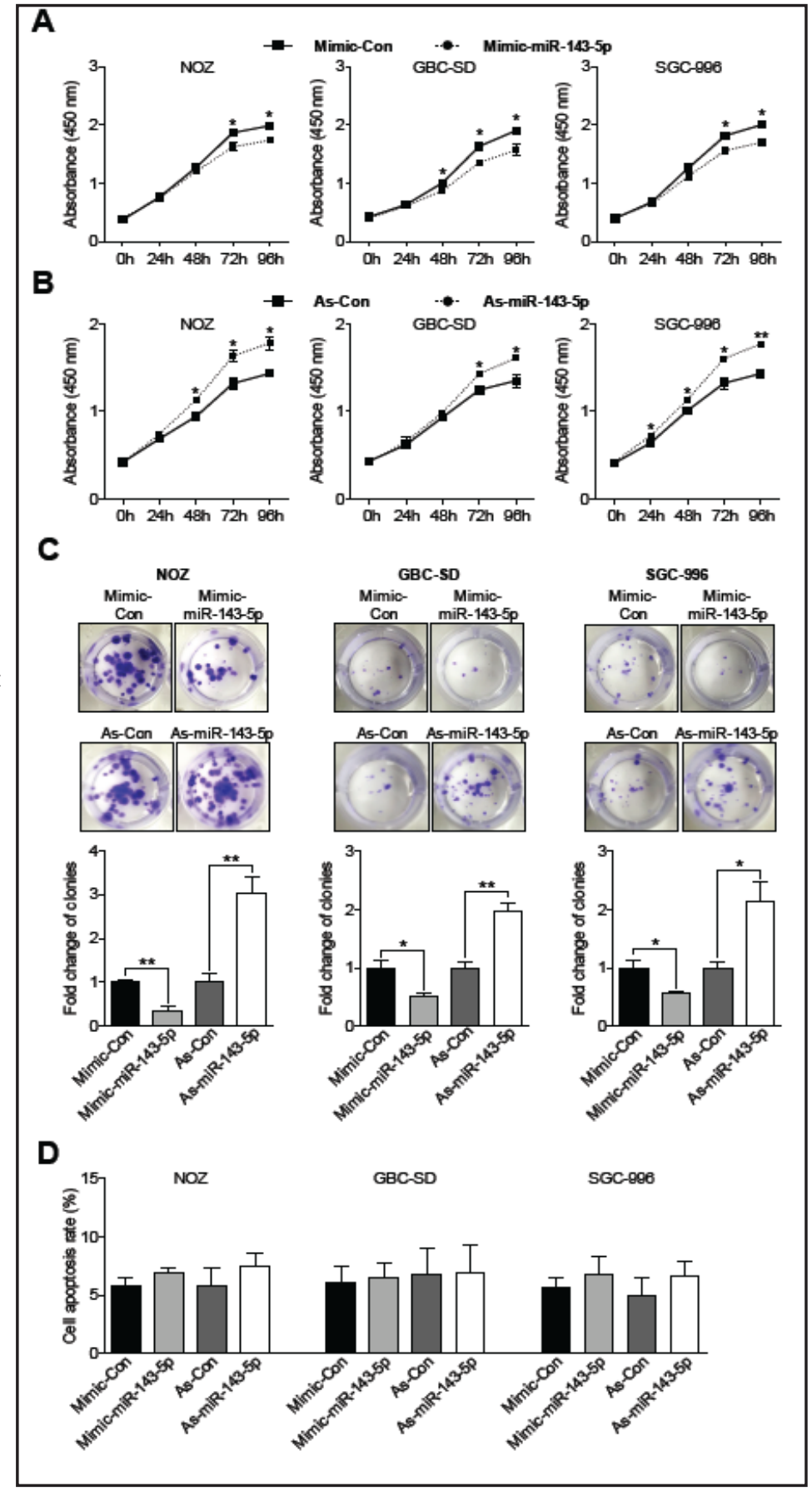


A

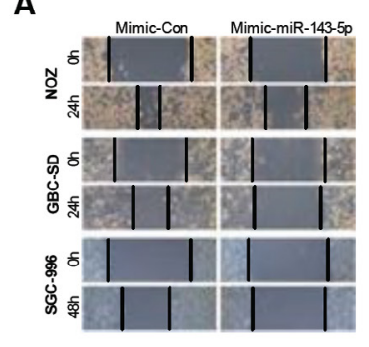

C

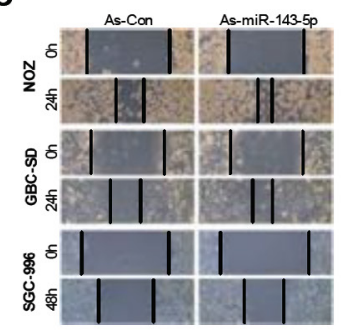

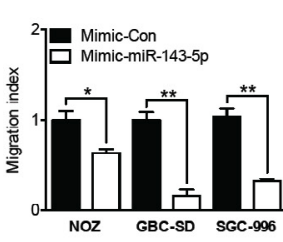

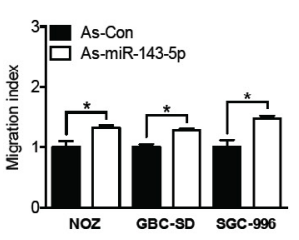

B
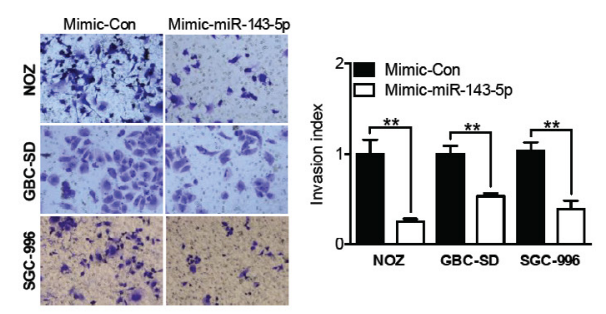

D

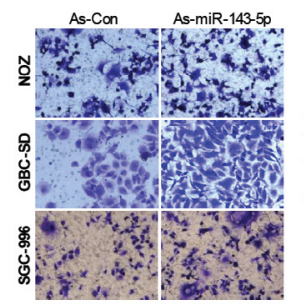

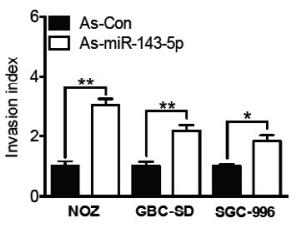

Fig. 3. In vitro altered miR-143-5p expression influenced GBC cells migration and invasion. (A-B) Enforced miR-143-5p expression affected GBC cells migration and invasion ability. (C-D) Lowering miR-143-5p expression increased GBC cells migration and invasion ability. Wound healing and transwell assay were performed in GBC cells transfected with miR-143-5p mimic, antisense and negative control. The experiments were repeated three times. ${ }^{*} P<0.05 ;{ }^{*} P<0.01$; Bar, SEM; Student's $t$ test.

(Fig. 1C), and several clinicopathological related markers and postoperative survival were analyzed simultaneously. Interestingly, higher miR-143-5p expression correlated well with a smaller tumor size and lower TNM stage (Fig. 1D-1E, Table 1). A significantly improved postoperative cumulative survival rate was also detected with elevated miR143-5p expression (Fig. 1F). We then evaluated whether miR-143-5p could serve as an independent prognostic factor by performing univariate and multivariate analyses using the Cox's proportional hazards model. The results showed that miR-143-5p level and TNM stage as independent prognostic factors for these GBC patients (Table 2). Taken together, these findings indicate that reduced miR-143-5p expression may play an important role in the development and progression of GBC.

\section{Elevated miR-143-5p expression inhibited GBC cells proliferation and metastasis}

For further elucidating the effect of miR-143-5p in GBC progression, miR-143-5p mimic (Mimic-miR-143-5p) and miR-143-5p antisense (As-miR-143-5p) were used in GBC cell lines (NOZ, GBC-SD and SGC-996) for altering miR-143-5p expression. MTS and colony formation assays were used for evaluating the effects of miR-143-5p on cell proliferation, wound healing and transwell assays were taken for detecting migration capacity. Consistent with previous clinical studies suggesting a tumor suppressor of miR-143-5p, NOZ, GBC-SD and SGC-996 transfected with miR-143-5p mimic manifested a remarkably lowered proliferation rate compared with cells transfected with negative controls (Fig. 2A-2B). Otherwise reducing miR-143-5p expression with amiR-143-5p antisense addition accelerated the proliferation capacity of GBC cell lines (Fig. 2A-2B). Furthermore, plate clone forming experiments also exhibited a clone formation inhibition effect with miR-143-5p mimic treatment and a favorable effect with miR-143-5p antisense addition (Fig. 2C).

The effects of miR-143-5p on cell migration and invasion were also analyzed. According to the results of the wound healing assay, GBC cells transfected with miR-143-5p mimic had a wider interval than the control and more narrow interval in miR-143-5p antisense treatment group (Fig. 3A-3B). Transwell assay showed that the percentage of migrated cells was significantly lower in GBC cells transfected with miR-143-5p mimic and higher in cells transfected with miR-143-5p antisense (Fig. 3C-3D). However, miR-143-5p has no effect on 


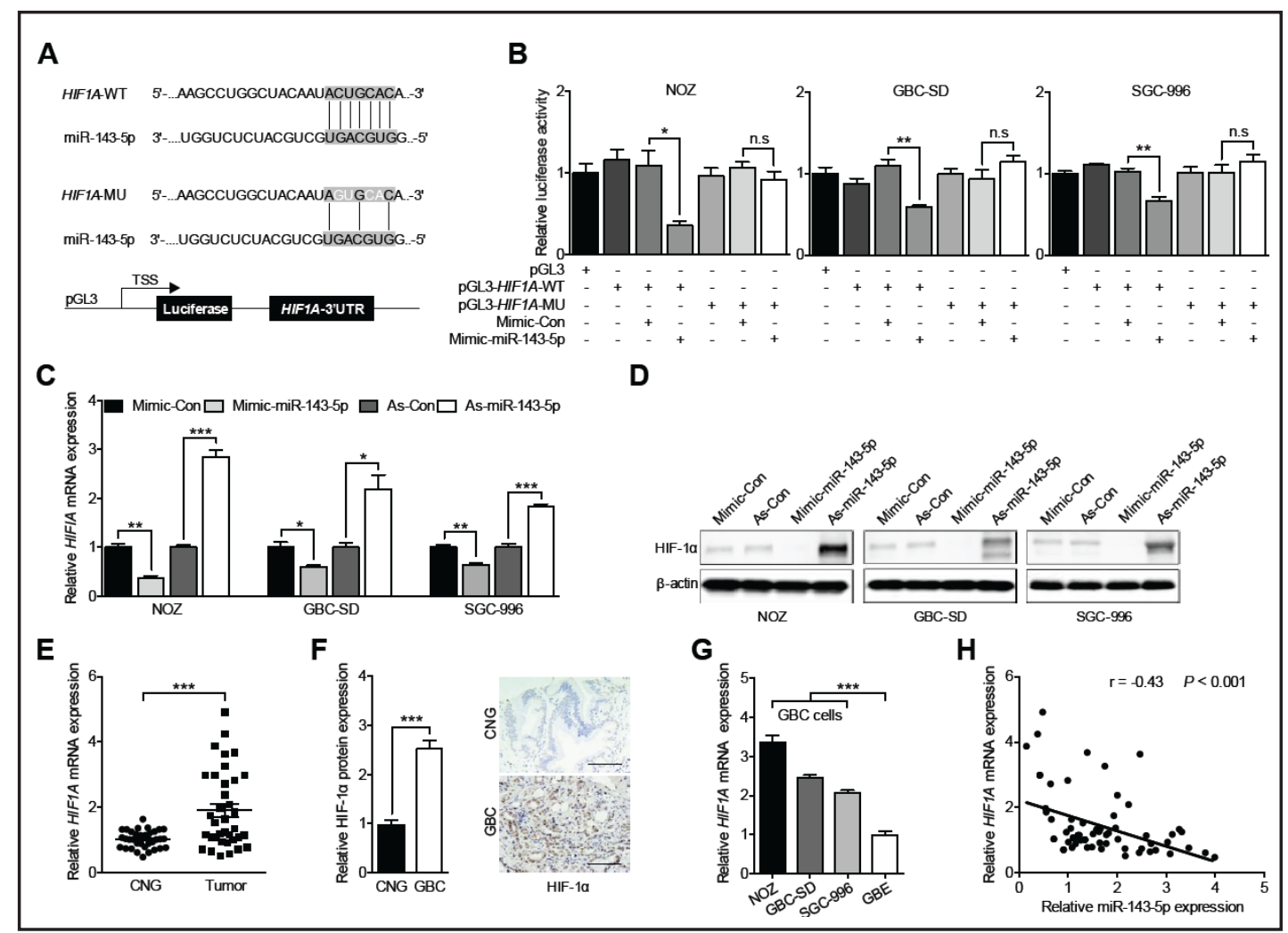

Fig. 4. miR-143-5p inhibits HIF-1 $\alpha$ expression by binding its 3 '-UTR. (A) Sequence of the miR-143-5p binding sites within the human HIF-1 $\alpha$ 3'-UTR and a schematic diagram of the reporter constructs showing the HIF-1 $\alpha$ 3'-UTR sequence (WT) and the mutated sequence (MU). (B) miR-143-5p overexpression reduced HIF-1 $\alpha$-WT luciferase activity, but failed in HIF-1 $\alpha$-MU group. Luciferase assays were done in 3 GBC cell lines. The results are displayed as the ratio of firefly luciferase activity in the miR-143-5p mimic-transfected cells to that in the control cells. (C-D) Q-PCR and western blot analysis of HIF-1 $\alpha$ mRNA and protein levels in GBC cells after transfection miR-143-5p mimic or antisense. (E) Increased HIF-1 $\alpha$ expression in GBC tumors analyzed by RT-PCR. (F) Elevated HIF-1 $\alpha$ expression in GBC tumors assessed by immunohistochemistry. (G) Increased HIF-1 $\alpha$ expression in GBC cell lines. $(\mathrm{H})$ Pearson's correlation scatter plot of HIF- $1 \alpha$ mRNA and miR-143-5p expression in GBC tumors. U6 small nuclear RNA and GAPDH were used as an internal control in Q-PCR. The experiments were repeated three times. ${ }^{*} P<0.05$; ${ }^{* *} P<0.01$; ${ }^{* * *} P<0.001$; Bar, SEM; Student's t test.

apoptosis of GBC cells (Fig. 2D). These results indicate that miR-143-5p could effectively suppress the growth, migration and invasion of GBC cells in vitro.

\section{HIF-1 $\alpha$ is a potential target of miR-143-5p}

For further identifying how miR-143-5p influenced GBC cells behavior, target prediction programs were utilized for prediction of the possible target genes of miR-143-5p. HIF$1 \alpha$, was eventually found to be a potential candidate target. For verifying this regulating mechanism truly existed, the 3'-UTR of HIF-1 $\alpha$, which was predicted could be interacted with miR-143-5p, was cloned into pGL3.0 luciferase reporter vector (Fig. 4A). miR-143-5p mimic overexpression significantly inhibited wild type HIF-1 $\alpha$ 3'-UTR luciferase activity. However, this regulatory effect was disappeared when a mutant 3'-UTR of HIF- $1 \alpha$, of which the miR-143-5p binding site was mutated. (Fig. 4B). In addition, miR-143-5p mimic addition decreased HIF-1 $\alpha$ mRNA and protein levels in GBC cells, while inhibition of endogenous miR143-5p increased HIF-1 $\alpha$ mRNA and protein expression (Fig. 4C-4D). 


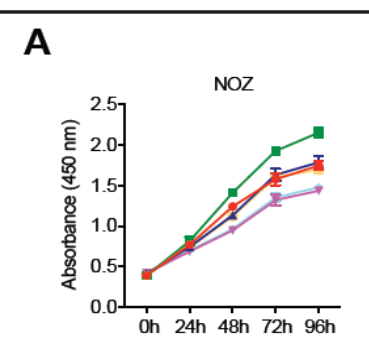

C
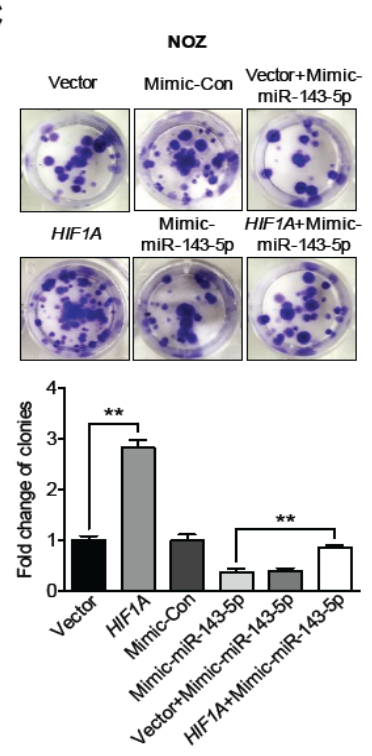

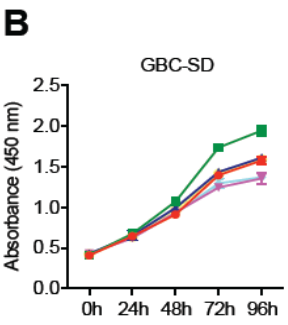

D

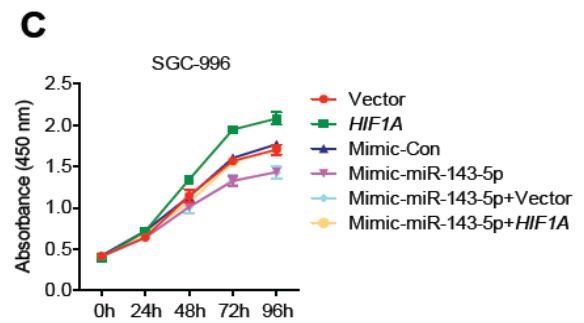

E
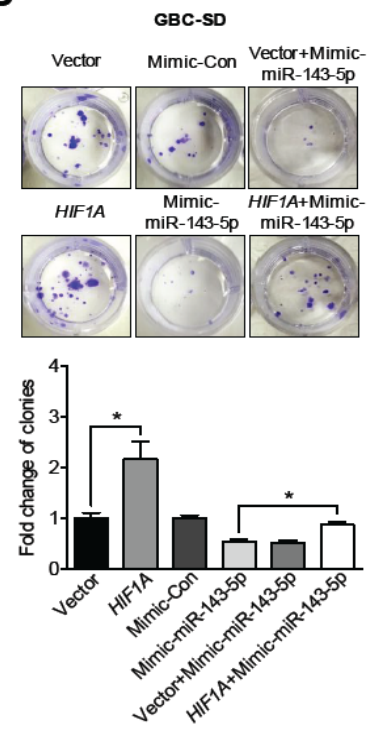
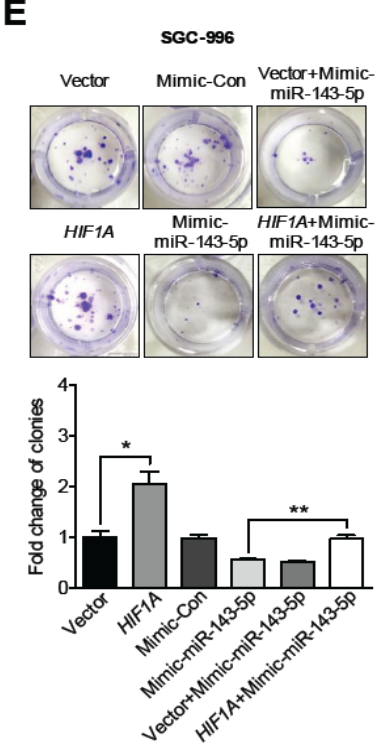

Fig. 5. HIF- $1 \alpha$ are involved in the role of miR-143-5p in regulation of GBC cell proliferation activity. (A-C) MTS analysis of GBC cells after transfection miR-143-5p mimic and HIF- $1 \alpha$. (D-F) Representative images (up) and quantification (down) of GBC cell colonies, as determined by colony formation assay after transfection miR-143-5p mimic and HIF-1 $\alpha$. All the experiments were repeated three times. ${ }^{*} P<0.05$; ${ }^{* *} P<0.01$; Bar, SEM; Student's t test.

We then examined HIF- $1 \alpha$ expression in 36 cases of GBC tissues and CNG tissues. Elevated HIF-1 $\alpha$ mRNA and protein expression were found in GBC tissues in significantly by using Q-PCR and IHC staining (Fig. 4E-4F). Also, we assessed the expression of HIF-1 $\alpha$ in different GBC cells and GBE cells, and found HIF-1 $\alpha$ had a relatively high level in GBC cells (Fig. 4G). An inverse relationship was found between miR-143-5p and HIF-1 $\alpha$ expression in GBC tumor samples (Fig. 4H).

For verifying whether the tumor inhibitory role of miR-143-5p was HIF-1 $\alpha$ dependent, GBC cells with miR-143-5p overexpression were then transfected HIF-1 $\alpha$. As expected, HIF$1 \alpha$ overexpression attenuated the anti-tumor role of miR-143-5p, as shown by increased GBC cell proliferation, migration and invasion (Fig. 5A-5G; Fig. 6A-6D). Taken together, these data suggest that miR-143-5p may suppress GBC cell proliferation and metastasis by targeting HIF- $1 \alpha$.

miR-143-5p can represses the expression of EMT and angiogenesis marker

EMT has been considered to be a key factor in regulating tumor invasion and metastasis in many cancers, including GBC. During EMT, epithelial cells lose expression of epithelial markers (E-cadherin, $\mathrm{N}$-cadherin, and fibronectin) and acquire a mesenchymal marker (Vimentin) induced by EMT related-transcription factor ( $\beta$-catenin and TWIST1), resulting in promoting tumor invasion and metastasis [26]. Vascular endothelial growth factor (VEGF) is an important angiogenesis marker, which plays a key role in cancer cell proliferation. Consistently, in our GBC tumors, accompanied with increased Ki- $67^{+}$cells (a cell proliferative 
Fig. 6. HIF- $1 \alpha$ are involved in the role of miR-143-5p in regulation of GBC cell migration and invasion ability. (A-B) Representative images and quantification of GBC cell migration and invasion activity, as determined by wound healing assay after transfection miR-143-5p mimic and HIF-1 $\alpha$. (C-D) Representative images $(\mathrm{C})$ and quantification (D) of GBC cell migration and invasion activity, as determined by transwell assay after transfection miR143-5p mimic and HIF-1 $\alpha$. All the experiments were repeated three times. ${ }^{*} P<0.05$; ** $P<0.01 ;$ Bar, SEM; Student's t test.

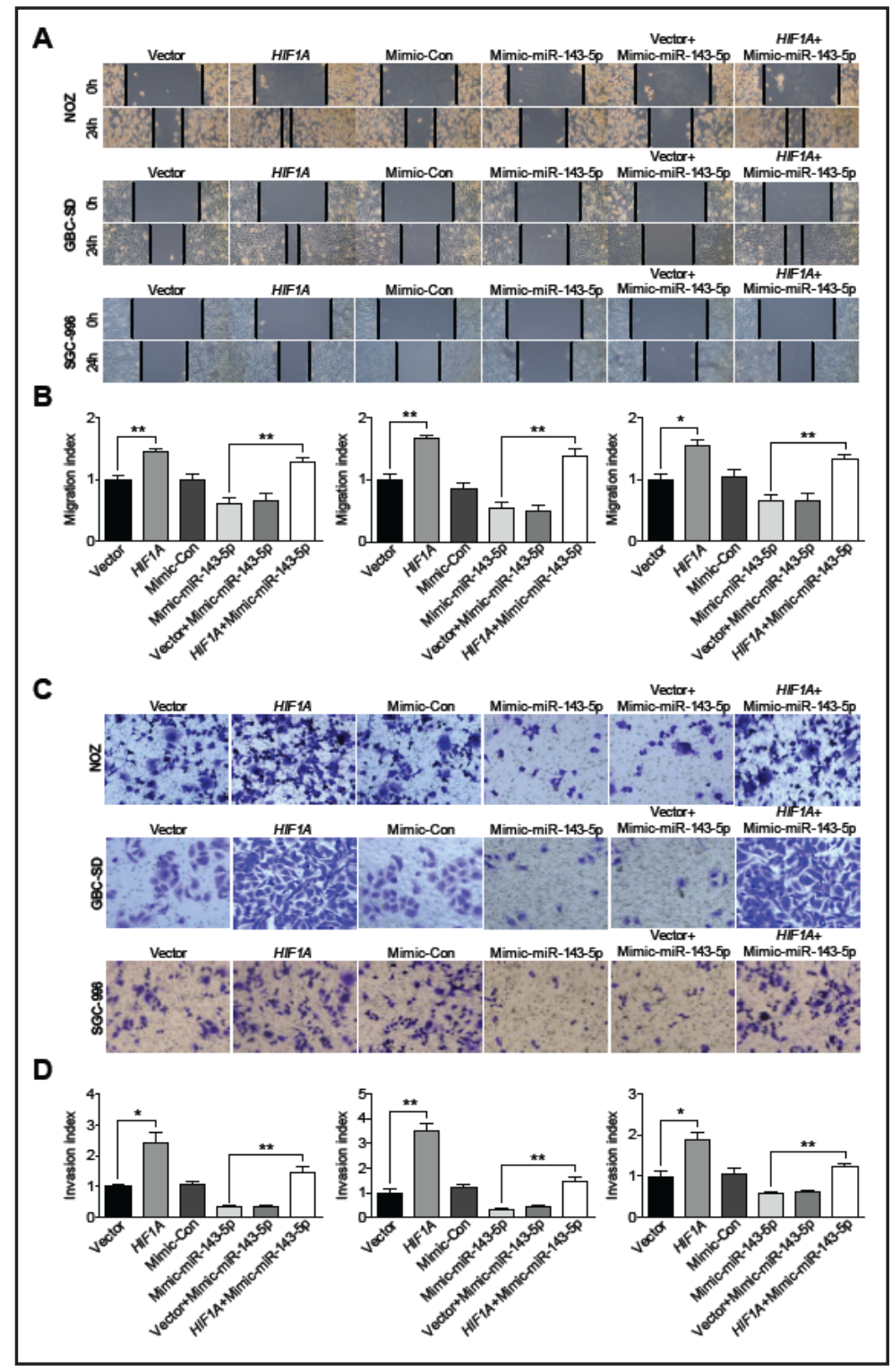

marker), high-TNM stage GBC tumors also manifested reduced epithelial marker E-cadherin and increased mesenchymal markers vimentin expression (Fig. 7A). Interestingly, we also found that tumors with lower miR-143-5p expression or higher HIF-1 $\alpha$ expression always manifested decreased epithelial marker E-cadherin expression and increased mesenchymal marker vimentin expression, Twist1 expression, and angiogenesis marker VEGF expression (Fig. 7B-7C). Ki-67 ${ }^{+}$and PCNA ${ }^{+}$cells were also elevated in GBC tumors with lower miR-143-5p expression (Fig. 7D). In addition, we detected the mRNA and protein levels of EMT markers, EMT-related transcription factor, and angiogenesis marker in paired transfected miR-143$5 p$ mimic or miR-143-5p antisense GBC cells. We found that miR-143-5p overexpression decreased $\beta$-catenin, Twist1, vimentin and VEGF expression levels, and otherwise increased E-cadherin expression. On the contrary, miR-143-5p inhibition had the opposite effect (Fig. $7 \mathrm{E}-7 \mathrm{H})$. These results support a role for miR-143-5p in modulating EMT process and cancer cell proliferation for GBC progression.

miR-143-5p inhibit the growth and liver metastasis in mouse models

For further analyzing the GBC tumor inhibitory role of miR-143-5p in vivo, GBC tumor xenografts model were then used to determine the functional roles of miR-143-5p in 


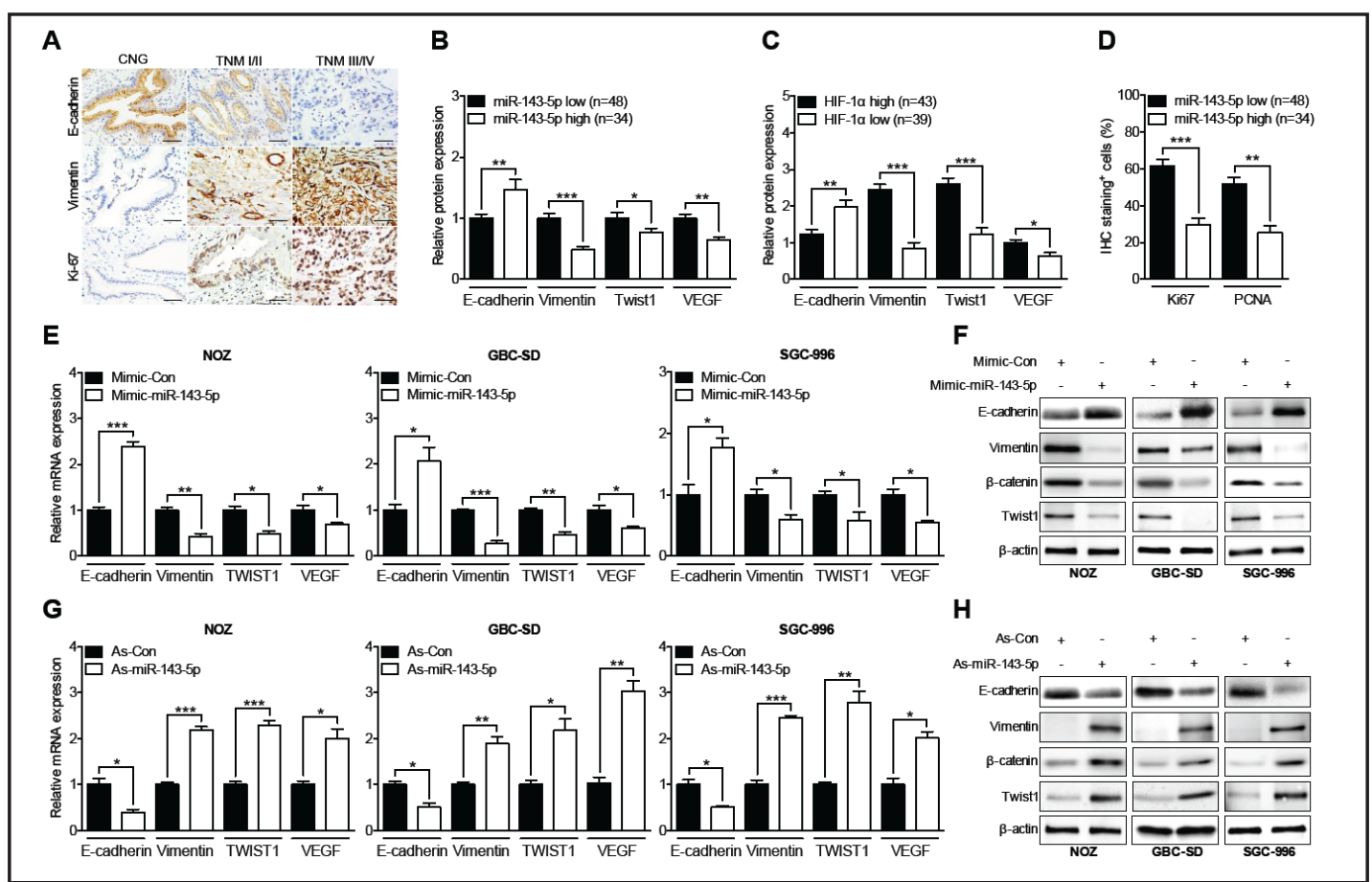

Fig. 7. miR-143-5p regulates EMT markers in GBC. (A) Clinical specimens of normal gallbladder epithelium and TNM I/II and III/IV were stained for E-cadherin, vimentin, and Ki-67. Representative images from IHC were shown. Original magnification, $\times 400$; scale bars: $100 \mu \mathrm{m}$. (B-C) Quantification of E-cadherin, vimentin, Twist1 and VEGF protein expression and in high and low miR-143-5p or HIF-1 $\alpha$ expression groups. (D) Quantification of Ki- $67^{+}$and $\mathrm{PCNA}^{+}$cell rate in high and low miR-143-5p expression groups. (E-H) Q-PCR and western blot analysis of EMT and angiogenesis markers (E-cadherin, vimentin, Twist1, $\beta$-catenin, and VEGF) mRNA and protein levels in GBC cells after transfection miR-143-5p mimic or antisense. GAPDH were used as an internal control in Q-PCR. All the experiments were repeated three times. ${ }^{*} P<0.05$; ${ }^{* *} P<0.01$; *** $P<0.001$; Bar, SEM; Student's t test.

controlling tumor growth and metastasis. After being implanted subcutaneously into male nude mice, NOZ cells stably expressing miR-143-5p (average tumor weight of $420 \pm 57 \mathrm{mg}$ ) showed slower tumor growth rates than controls (average tumor weight of $1190 \pm 136 \mathrm{mg}$ ) (Fig. 8A-8C). Strikingly, NOZ cells with miR-143-5p overexpression exhibited significantly reduced liver metastasis rate (Fig. 8D-8E). Ki-67 and PCNA staining of xenografts showed an average $29 \%$ and $55 \%$ reduction of $\mathrm{Ki}-67^{+}$and $\mathrm{PCNA}^{+}$cells in the miR-143-5p overexpression group compared with control group (Fig. 8F-8G). Moreover, miR-143-5p overexpression xenografts showed reduced HIF- $1 \alpha$, VEGF, $\beta$-catenin, vimentin and Twist1 staining, and otherwise epithelial markers E-cadherin was increased (Fig. 8G). These results from GBC xenograft mouse models provide further support tumor inhibitory role of miR-143-5p.

\section{Discussion}

GBC is a malignant cancer with very poor prognosis for its high metastasis propensity at an early time [27]. But the mechanism underlying its high proliferation rate and easy metastasis were still poorly understood. Cumulatively evidence indicated miRNA play a crucial role in the tumor pathophysiology by directly regulating vital oncogene or tumor suppressor $[28,29]$. The association of aberrant miRNA with GBC tumorigenesis and progression have been revealed in numerous studies. miR-143-5p can repress tumor proliferation and metastasis by targeting different oncogenes. Studies by Liu et al. showing 


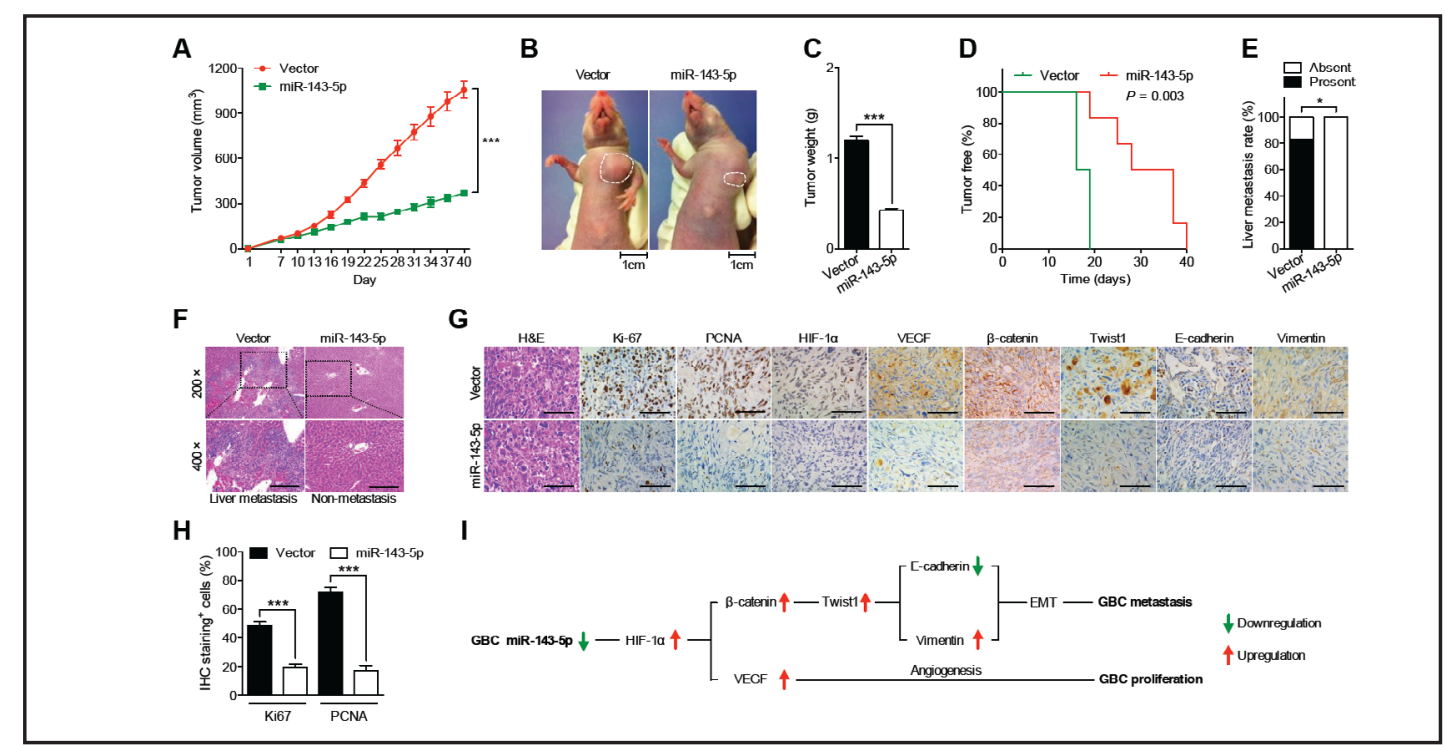

Fig. 8. miR-143-5p inhibits GBC cells growth and metastasis by inhibiting HIF-1 $\alpha$ and EMT pathway in vivo. (A) Growth curves of tumors resulted from injection of NOZ cells stably expressing with miR-143-5p in nude mice. (B) Representative tumor image of the paired groups was shown. (C) Quantification analysis of tumor weight in the paired groups. (D) Log-rank test analysis of tumor free rate (under the naked eye) in the paired groups. (E) Quantification analysis of liver metastasis in the paired groups. (F) Representative image of liver metastasis from the paired groups. (G) H\&E and IHC analysis of HIF-1 $\alpha$, Ki-67, PCNA, VEGF, $\beta$-catenin, Twist1, E-cadherin and vimentin expression in NOZ tumor xenografts stably overexpressing with miR-1435p. Representative images from 6 separate samples were shown. Original magnification, $\times$ 400; scale bars: $100 \mu \mathrm{m}$. (H) Ki-67+ and $\mathrm{PCNA}^{+}$cell rate analysis of tumor xenografts in the paired groups. (I) Schematic representation of pathways modulated by miR-143-5p in GBC cells. Downregulation of miR-143-5p in GBC cells can elevate HIF-1 $\alpha$ expression. This increases the expression of angiogenesis and EMT-related factors, including VEGF and $\beta$-catenin, resulting in tumor cell proliferation, metastasis, and pathogenesis of GBC. * $P$ $<0.05 ;{ }^{* * *} P<0.001 ; \mathrm{n}=6$, Bar, SEM; Student's t test.

that miR-143-5p can inhibit cell cycle and epithelial-mesenchymal transition signaling by targeting STAT3 in esophageal squamous cell carcinoma [8]. In addition, miR-143-5p can produce a significant growth inhibitory effect by directly targeting COX-2 in gastric cancer [30]. miR-143-5p can also suppress bladder cancer cell proliferation through degrading vital oncogene KAS in tumorigenesis [31].

In this study, Q-PCR results from 36 cases of GBC tissues and CNG tissues found a lower miR-143-5p expression in GBC. Besides, we demonstrated miR-143-5p lower expression was also associated with large tumor size, late TNM stage and poor overall survival. To identify the biological function of miR-143-5p, we constructed miR-143-5p knockdown and overexpression GBC cell lines, results showed miR-143-5p knockdown can promote tumor migration, invasion and proliferation, while miR-143-5p overexpression had the opposite effect. In addition to in vivo experiments, miR-143-5p can also inhibit the growth and liver metastasis in mouse model. All the results above suggested miR-143-5p played a tumor suppressor role in GBC progression.

Further, to explore the underlying mechanism how miR-143-5p suppressed tumor progression, we used target prediction programs to predict genes that were possibly targeted by miR-143-5p. Finally, we found HIF- $1 \alpha$ was directly targeted by miR-143-5p. Because of the fast rate of cancer cell proliferation, the existing vasculature can not maintain the supply of oxygen. The fast proliferation rate and lacking enough oxygen of supplying cancer cells made low oxygen tension an important hallmark of solid tumors.

The tumor cells adapt to the hypoxic microenvironment mainly via the regulation of hypoxia-inducible factor (HIF) family of transcription factors. HIF-1 $\alpha$, a master regulator KARGER 
of hypoxia, significantly increased in cancer compared with normal tissues. Indeed, HIF$1 \alpha$ activation has been taken as vital prognostic indicator in numerous cancers $[32,33]$. HIF- $1 \alpha$ regulated genes play crucial roles in the oxygen homeostasis, energy metabolism, angiogenesis and proliferation. Moreover, HIF- $1 \alpha$ is also critically important for tumor invasion and metastasis. Liao et al. generated a transgenic mouse model to conditionally delete HIF- $1 \alpha$ and results showed HIF-1 $\alpha$ deletion can retard tumor growth and suppress pulmonary metastases [34]. EMT transition is a major process of tumor metastasis. In renal clear cell carcinoma, von Hippel-Lindau tumor suppressor (VHL), a well-known negative regulator of HIF- $1 \alpha$, is loss of function. HIF- $1 \alpha$ can reduce E-cadherin expression in the VHL-deficient manner [35]. Meanwhile, the mechanisms contributing to HIF-1 $\alpha$ activation in cancer are complicated. It can be activated by the argument of tumor hypoxia condition and also be suppressed by lots of cancer suppressor genes. In this study, we found miR-143-5p functioned as a tumor suppressor gene via targeting HIF-1 $\alpha$. Nevertheless, previous studies confirmed HIF- $1 \alpha$ played crucial role in GBC progression, assuming miR-143-5p suppressed tumor progression through regulation of HIF-1 $\alpha$. Later studies confirmed this hypothesis. miR-143-5p can directly interact with the 3'-UTR of HIF- $1 \alpha$ and decrease its expression. HIF$1 \alpha$ overexpression had a similar effect on migration, invasion and proliferation as miR-143$5 p$ knockdown. Besides, miR-143-5p can reverse the oncogenic effect induced by HIF-1 $\alpha$ overexpression. In brief, the results suggested the tumor suppressor role of miR-143-5p was partially dependent on the suppression of HIF-1 $1 \alpha$ via the direct interaction with its 3'-UTR.

To conclude, our studies showed miR-143-5p was downregulated in GBC tissues and was inversely correlated with the tumor size and clinical TNM stage. Besides, both in vivo and in vitro experiments clarified that enhanced expression of miR-143-5p suppressed proliferation, migration and invasion by targeting HIF- $1 \alpha$. Our experiments identify a new tumor suppressor in GBC and address its mechanism to inhibit tumor progression. Thus, in consideration of its significant value in medical treatment, miR-143-5p may be a promising tumor biomarker for early diagnosis and prognostic indicator. Additionally, it can be taken as a critical therapeutic target and applied to clinical treatment. Further studies are needed to focus on the molecular mechanism concerning the tumor hypoxia. As tumor hypoxia is a complicated network, an in-depth study will help us to figure out the role of miR-143-5p in hypoxia response.

\section{Acknowledgements}

This work was supported by the National Science Foundation of China (81072011, 81272748, and 81472240), Foundation of Science and Technology Commission of Shanghai Municipality (12XD1403400), and Foundation of Shanghai Municipal Health Bureau (XBR2011035).

\section{Disclosure Statement}

The authors declare no conflict of interest.

\section{References}

1 Jemal A, Siegel R, Xu J, Ward E: Cancer statistics, 2010. CA Cancer J Clin 2010;60:277-300.

2 Bartlett DL, Fong Y, Fortner JG, Brennan MF, Blumgart LH: Long-term results after resection for gallbladder cancer. Implications for staging and management. Ann Surg 1996;224:639-646.

3 Wullstein C, Woeste G, Barkhausen S, Gross E, Hopt UT: Do complications related to laparoscopic cholecystectomy influence the prognosis of gallbladder cancer? Surg Endosc 2002;16:828-832.

4 Bartel DP: MicroRNAs: genomics, biogenesis, mechanism, and function. Cell 2004;116:281-297. 


\section{Cellular Physiology Cell Physiol Biochem 2017;42:2078-2092 \begin{tabular}{ll|l} 
and Biochemistry Published online: August 11, 2017 & $\begin{array}{l}\text { (c) } 2017 \text { The Author(s). Published by S. Karger AG, Basel } \\
\text { www.karger.com/cpb }\end{array}$
\end{tabular}}

He et al.: MiR-143-5p Inhibits Gallbladder Cancer Metastasis

5 Kloosterman WP, Plasterk RH: The diverse functions of microRNAs in animal development and disease. Dev Cell 2006;11:441-450.

6 Croce CM, Calin GA: miRNAs, cancer, and stem cell division. Cell 2005;122:6-7.

7 Chandra V, Kim JJ, Mittal B, Rai R: MicroRNA aberrations: An emerging field for gallbladder cancer management. World J Gastroenterol 2016;22:1787-1799.

8 Chivukula RR, Shi G, Acharya A, Mills EW, Zeitels LR, Anandam JL, Abdelnaby AA, Balch GC, Mansour JC, Yopp AC, Maitra A, Mendell JT: An essential mesenchymal function for miR-143/145 in intestinal epithelial regeneration. Cell 2014;157:1104-1116.

-9 He Z, Yi J, Liu X, Chen J, Han S, Jin L, Chen L, Song H: MiR-143-3p functions as a tumor suppressor by regulating cell proliferation, invasion and epithelial-mesenchymal transition by targeting QKI-5 in esophageal squamous cell carcinoma. Mol Cancer 2016;15:51.

10 Li F, Li S, Cheng T: TGF-beta1 promotes osteosarcoma cell migration and invasion through the miR-143versican pathway. Cell Physiol Biochem 2014;34:2169-2179.

11 Liu J, Mao Y, Zhang D, Hao S, Zhang Z, Li Z, Li B: MiR-143 inhibits tumor cell proliferation and invasion by targeting STAT3 in esophageal squamous cell carcinoma. Cancer Lett 2016;373:97-108.

-12 Wang Q, Cai J, Wang J, Xiong C, Zhao J: MiR-143 inhibits EGFR-signaling-dependent osteosarcoma invasion. Tumour Biol 2014;35:12743-12748.

13 Yan X, Chen X, Liang H, Deng T, Chen W, Zhang S, Liu M, Gao X, Liu Y, Zhao C, Wang X, Wang N, Li J, Liu R, Zen K, Zhang CY, Liu B, Ba Y: miR-143 and miR-145 synergistically regulate ERBB3 to suppress cell proliferation and invasion in breast cancer. Mol Cancer 2014;13:220.

14 Chang Y, Liu C, Yang J, Liu G, Feng F, Tang J, Hu L, Li L, Jiang F, Chen C, Wang R, Yang Y, Jiang X, Wu M, Chen L, Wang H: MiR-20a triggers metastasis of gallbladder carcinoma. J Hepatol 2013;59:518-527.

15 He J, Shen S, Lu W, Zhou Y, Hou Y, Zhang Y, Jiang Y, Liu H, Shao Y: HDAC1 promoted migration and invasion binding with TCF12 by promoting EMT progress in gallbladder cancer. Oncotarget 2016;7:32754-32764.

16 Brooks DL, Schwab LP, Krutilina R, Parke DN, Sethuraman A, Hoogewijs D, Schorg A, Gotwald L, Fan M, Wenger RH, Seagroves TN: ITGA6 is directly regulated by hypoxia-inducible factors and enriches for cancer stem cell activity and invasion in metastatic breast cancer models. Mol Cancer 2016;15:26.

17 Hou SY, Li YP, Wang JH, Yang SL, Wang Y, Wang Y, Kuang Y: Aquaporin-3 Inhibition Reduces the Growth of NSCLC Cells Induced by Hypoxia. Cell Physiol Biochem 2016;38:129-140.

-18 Huang S, Guo Y, Jacobi A, Li Z, Huang S, He J, Liu X, Tang Y: Aromatic Hydrocarbon Receptor Suppresses Prostate Cancer Bone Metastasis Cells-Induced Vasculogenesis of Endothelial Progenitor Cells under Hypoxia. Cell Physiol Biochem 2016;39:709-720.

19 Kai AK, Chan LK, Lo RC, Lee JM, Wong CC, Wong JC, Ng IO: Down-regulation of TIMP2 by HIF-1alpha/ miR-210/HIF-3alpha regulatory feedback circuit enhances cancer metastasis in hepatocellular carcinoma. Hepatology 2016;64:473-487.

20 Meng F, Chen X, Song H, Lou G: LAPTM4B down regulation inhibits the proliferation, invasion and angiogenesis of HeLa cells in vitro. Cell Physiol Biochem 2015;37:890-900.

-21 Shi CY, Fan Y, Liu B, Lou WH: HIF1 contributes to hypoxia-induced pancreatic cancer cells invasion via promoting QSOX1 expression. Cell Physiol Biochem 2013;32:561-568.

-22 Wang F, Zhang H, Xu N, Huang N, Tian C, Ye A, Hu G, He J, Zhang Y: A novel hypoxia-induced miR-147a regulates cell proliferation through a positive feedback loop of stabilizing HIF-1alpha. Cancer Biol Ther 2016;17:790-798.

23 Livak KJ, Schmittgen TD: Analysis of relative gene expression data using real-time quantitative PCR and the 2(-Delta Delta C(T)) Method. Methods 2001;25:402-408.

24 Zhan M, Wang H, Chen T, Chen W, Yang L, He M, Xu S, Wang J: NOX1 mediates chemoresistance via HIF1alpha/MDR1 pathway in gallbladder cancer. Biochem Biophys Res Commun 2015;468:79-85.

25 Tomayko MM, Reynolds CP: Determination of subcutaneous tumor size in athymic (nude) mice. Cancer Chemother Pharmacol 1989;24:148-154.

26 Lamouille S, Xu J, Derynck R: Molecular mechanisms of epithelial-mesenchymal transition. Nat Rev Mol Cell Biol 2014;15:178-196.

27 Kakaei F, Beheshtirouy S, Nejatollahi SM, Zarrintan S, Mafi MR: Surgical treatment of gallbladder carcinoma: a critical review. Updates Surg 2015;67:339-351.

28 Chen Y, Gao Y, Zhang K, Li C, Pan Y, Chen J, Wang R, Chen L: MicroRNAs as Regulators of Cisplatin Resistance in Lung Cancer. Cell Physiol Biochem 2015;37:1869-1880. 


\section{Cellular Physiology Cell Physiol Biochem 2017;42:2078-2092 \begin{tabular}{l|l} 
DOI: 10.1159/000479903 & $\begin{array}{l}\text { O 2017 The Author(s). Published by S. Karger AG, Basel } \\
\text { www.karger.com/cpb }\end{array}$ \\
\hline
\end{tabular} \\ He et al.: MiR-143-5p Inhibits Gallbladder Cancer Metastasis}

29 Shao Y, Geng Y, Gu W, Huang J, Pei H, Jiang J: Prognostic role of tissue and circulating microRNA-200c in malignant tumors: a systematic review and meta-analysis. Cell Physiol Biochem 2015;35:1188-1200.

-30 Wu XL, Cheng B, Li PY, Huang HJ, Zhao Q Dan ZL, Tian DA, Zhang P: MicroRNA-143 suppresses gastric cancer cell growth and induces apoptosis by targeting COX-2. World J Gastroenterol 2013;19:7758-7765.

-31 Noguchi S, Mori T, Hoshino Y, Maruo K, Yamada N, Kitade Y, Naoe T, Akao Y: MicroRNA-143 functions as a tumor suppressor in human bladder cancer T24 cells. Cancer Lett 2011;307:211-220.

- 32 Birner P, Schindl M, Obermair A, Plank C, Breitenecker G, Oberhuber G: Overexpression of hypoxiainducible factor 1 alpha is a marker for an unfavorable prognosis in early-stage invasive cervical cancer. Cancer Res 2000;60:4693-4696.

33 Zagzag D, Zhong H, Scalzitti JM, Laughner E, Simons JW, Semenza GL: Expression of hypoxia-inducible factor 1alpha in brain tumors: association with angiogenesis, invasion, and progression. Cancer 2000;88:2606-2618.

-34 Liao D, Corle C, Seagroves TN, Johnson RS: Hypoxia-inducible factor-1alpha is a key regulator of metastasis in a transgenic model of cancer initiation and progression. Cancer Res 2007;67:563-572.

-35 Krishnamachary B, Zagzag D, Nagasawa H, Rainey K, Okuyama H, Baek JH, Semenza GL: Hypoxia-inducible factor-1-dependent repression of E-cadherin in von Hippel-Lindau tumor suppressor-null renal cell carcinoma mediated by TCF3, ZFHX1A, and ZFHX1B. Cancer Res 2006;66:2725-2731. 